Check for updates

Cite this: RSC Adv., 2018, 8, 36512

Received 9th September 2018 Accepted 19th October 2018

DOI: $10.1039 / c 8 r a 07518 b$

rsc.li/rsc-advances

\section{In vitro and in vivo evaluations of mechanical properties, biocompatibility and osteogenic ability of sintered porous titanium alloy implant}

\author{
Ji Li, (D) a Zhongli Li, ${ }^{\text {aa }}$ Ruiling Li, ${ }^{\mathrm{b}}$ Yueyi Shi, ${ }^{\mathrm{c}}$ Haoran Wang, ${ }^{\mathrm{a}}$ Yuxing Wang ${ }^{\mathrm{a}}$ \\ and Gong Jin ${ }^{d}$
}

A new sintering technique using $\mathrm{Ti}_{6} \mathrm{Al}_{4} \mathrm{~V}$ powder suspension was performed to prepare porous $\mathrm{Ti}_{6} \mathrm{Al}_{4} \mathrm{~V}$ alloys. The porous alloys could be fabricated with different porosities and pore sizes by controlling the quantity and size of spacer particles added to the $\mathrm{Ti}_{6} \mathrm{Al}_{4} \mathrm{~V}$ powder. The characteristics and biological properties of the porous $\mathrm{Ti}_{6} \mathrm{Al}_{4} \mathrm{~V}$ with two different porosities were evaluated by mechanical tests, cell tests and implantation. Dense $\mathrm{Ti}_{6} \mathrm{Al}_{4} \mathrm{~V}$ was used as the control. Compared with the control group, the porous $\mathrm{Ti}_{6} \mathrm{Al}_{4} \mathrm{~V}$ showed good biocompatibility and osteogenic ability, which makes this type of porous alloy a good prospective material for biomedical application. And compared with $50 \%$ porosity, the alloy with $75 \%$ porosity had the optimal mechanical properties, and suitable pore size and porosity, which allowed more bone ingrowth.

\section{Introduction}

Titanium alloys have been widely used in orthopedic and dental implants due to their low density, excellent mechanical properties, favorable biocompatibility, and good corrosion resistance. ${ }^{1}$ However, the high potential for aseptic loosening of the implant is still a principal issue. ${ }^{2}$ Clinical practices and studies have shown that the mechanical mismatch between metallic implant and natural bone may lead to stress-shielding (the elastic modulus of $\mathrm{Ti}_{6} \mathrm{Al}_{4} \mathrm{~V}$ is approximately $115 \mathrm{GPa}$ while that of cancellous and cortical bone are 0.2-2 GPa and 12-18 GPa, respectively), and thus cause bone resorption and eventually the failure of metallic implant fixation. ${ }^{3}$ Besides, the weak interfacial bonding between the implant and the bone (poor osseointegration) and a lack of biological anchorage for tissue ingrowth also cannot be ignored. ${ }^{4}$

Porous metallic structures can be utilized to overcome these drawbacks. ${ }^{5} \mathrm{~A}$ certain degree of porosity reduces the elastic modulus of metal and the stiffness mismatch between bone and implant and can hence ameliorate the effects of stress shielding on bone resorption. ${ }^{6,7}$ Additionally, porous metals allow bone growth into the pores that promote optimum osteointegration and strengthen the bone-implant interface,

aDepartment of Orthopedics, General Hospital of PLA, No. 28 Fuxing Road, Haidian District, Beijing 100853, China. E-mail: lizhongli@263.net; Fax: +86010 66938306; Tel: +8601066938306

${ }^{b}$ State Key Laboratory of Materials, Department of Materials Science and Engineering, Zhejiang University, Hangzhou 310027, China

'Department of Stomatology, General Hospital of PLA, No. 28 Fuxing Road, Haidian District, Beijing 100853, China

${ }^{d}$ ZhongAoHuiCheng Technology Co., No. 20 Kechuang Road, Economic and Technological Development Zone, Beijing 100176, China eventually enhancing bone-material contact and stability. ${ }^{8}$ Porosity and pore diameter are two of the most important parameters in biological porous materials that directly affect the interaction between cells, ${ }^{9}$ and the influences of porosity, pore size, and spatial arrangement on the biological behavior of bone have been investigated in several studies., ${ }^{2,10,11}$ Porous Ti alloy is an obvious choice considering the proven biocompatibility of titanium alloy in orthopedic applications. ${ }^{12}$ Many techniques have been investigated to produce porous metallic structure, including powder sintering approach, space holder method, combustion synthesis, plasma spraying, and polymeric sponge replication. ${ }^{13,14}$ However, these conventional techniques result in low porosity and high possibility of pore blockage and have very limited control of the internal pore architecture and external shape of the porous titanium implants, hindering the further application of porous titanium.

Recently, a novel powder sintering process for the fabrication of porous titanium was developed..$^{15}$ This process consists of preparing a $\mathrm{Ti}_{6} \mathrm{Al}_{4} \mathrm{~V}$ powder suspension before a two-step slow thermal treatment under an inert gas or vacuum atmosphere, resulting of the implant with high ductility and porosity, and its microstructure is similar to natural human cortical bone. The implants could be fabricated with different porosities and pore sizes by controlling the quantity and size of spacer particles added to the $\mathrm{Ti}_{6} \mathrm{Al}_{4} \mathrm{~V}$ powder or the sintering temperatures, and the binder used had clean decomposition characteristics and left no residue after sintering at more than $1200{ }^{\circ} \mathrm{C}$. The potential to optimize mechanical and biological properties through the control of structural properties such as porosity and pore size makes this type of porous $\mathrm{Ti}_{6} \mathrm{Al}_{4} \mathrm{~V}$ attractive, and this technique is suit for large-scale application because of the low costs and low level of contaminations. To 
assess the characteristics, biocompatibility and osteogenic ability of the porous $\mathrm{Ti}_{6} \mathrm{Al}_{4} \mathrm{~V}$ prepared by the new sintering technique, we performed mechanical tests, in vitro cell tests and in vivo implantation in this study.

\section{Materials and methods}

\subsection{Samples preparations}

$\mathrm{Ti}_{6} \mathrm{Al}_{4} \mathrm{~V}$ powder (purity $\geq 99.5 \%$, particle size $<100 \mu \mathrm{m}$ ) was used as the starting material in the present study. The samples were produced as described previously. ${ }^{15}$ Initially, a powder


agar $\left(3.18 \%\right.$ on $\mathrm{H}_{2} \mathrm{O}$ ), 6 g Tergitol TMN 10 (2\% on Ti), $3 \mathrm{~g}$ Triton ( $1 \%$ on $\mathrm{Ti}$ ) and $0.36 \mathrm{~g}$ ammonium alginate $\left(0.18 \%\right.$ on $\left.\mathrm{H}_{2} \mathrm{O}\right)$. It is mixed during $6 \mathrm{~min}$ at $70{ }^{\circ} \mathrm{C}$ to obtain a fluid foam. The foam is cast into a mould and cooled down until the structure is gelled. After demoulding, the structure is dried at atmospheric pressure and room temperature. Then, the green artifact was calcined with a slow heating step at a rate lower than or equal to $20{ }^{\circ} \mathrm{C}$ per hour to a temperature between 400 and $600{ }^{\circ} \mathrm{C}$ under an inert atmosphere (Ar) or at a pressure more than $10^{-3} \mathrm{mbar}$ and constant temperature for $2 \mathrm{~h}$. Then, the artifact was sintered with slow heating to a temperature between $1200{ }^{\circ} \mathrm{C}$ and $1500{ }^{\circ} \mathrm{C}$ under vacuum or at a pressure more than $10^{-4} \mathrm{mbar}$ and constant temperature for $2 \mathrm{~h}$.

Porous Ti alloy samples were divided into two groups with different sintering temperatures and porosities, namely, the $50 \%$ porosity group and the $75 \%$ porosity group. Solid $\mathrm{Ti}_{6} \mathrm{Al}_{4} \mathrm{~V}$ was used as the control group, namely, the dense group. Each group had three types of samples: rod specimens $8 \mathrm{~mm}$ in diameter and $20 \mathrm{~mm}$ in length were used for the mechanical tests; disc specimens $1 \mathrm{~mm}$ thick and $10 \mathrm{~mm}$ in diameter were used for the in vitro cell tests; rod specimens $2 \mathrm{~mm}$ in diameter and $6 \mathrm{~mm}$ in length were used for the in vivo animal experiments. All the samples were ultrasonically treated in order to remove impurities. First, they were ultrasonically cleaned for $5 \mathrm{~min}$ each in two successive baths and then three times for 5 min in ultra-pure water. Afterwards, the scaffolds were dried in air in a sterile environment. The samples were then sealed in sterile bags and steam autoclaved for $15 \mathrm{~min}$ at $120^{\circ} \mathrm{C}$.

\subsection{Characterization}

The microstructures and surface topography of the samples were examined using optical microscopes. A scanning electron microscope (SEM) was employed to qualitatively determine the microtopography (surface morphology, pore size and interconnectivity) of the porous $\mathrm{Ti}$ alloy. Appropriate scanning photographs were chosen. Each sample was observed from three selected views. Ten aperture values were measured in each view. Then, the average pore diameter values were calculated. Porosity was calculated for each porous sample. Bulk density $(q)$ of the sample was determined by measuring the physical dimensions and mass of the sample. Apparent density $\left(q^{\prime}\right)$ was measured in water using Archimedes principle. The metal volume fraction $(\mathrm{VF})$ was calculated as: $\mathrm{VF}=q / q^{\prime}$. Porosity $(P)$ was then calculated as $P=1-\mathrm{VF}=1-\left(q / q^{\prime}\right)$.

\subsection{Mechanical properties}

Axial compression tests were done to evaluate the stiffness of the porous alloy samples as per ASTM D695-02 using an MTS Alliance RT30 electromechanical test frame (MTS systems, MN). A compressive test to failure was done at a crosshead speed of $0.5 \mathrm{~mm} \mathrm{~min}^{-1}$. The maximum load of the machine was 20000 N. Real-time compressive load versus displacement was continuously monitored and recorded. The stress-strain curves were generated for each sample set. Average values of compressive strength of the sample groups were taken as the compressive strength value for the given porosity. The elastic modulus was calculated from the slope of the compressive stress-strain curve in the linear elastic region.

\subsection{In vitro biochemical assays}

2.4.1 Cell culture. Osteoblastic (OB) cells were isolated from the calvaria of new born New Zealand rabbit. ${ }^{\mathbf{1 6}}$ Cells were cultured in Dulbecco's modified eagle medium (DMEM) (Gibco, USA) supplemented with $10 \%$ fetal bovine serum (FBS) and $1 \%$ penicillin/streptomycin and incubated at $37{ }^{\circ} \mathrm{C}$ in a $5 \% \mathrm{CO}_{2}$, $100 \%$ relative humidity incubator. Third passage cells were used in the present study.

2.4.2 Cell proliferation and attachment. A cell suspension $\left(2.5 \times 10^{5}\right.$ cells per $\left.\mathrm{mL}, 40 \mu \mathrm{l}\right)$ was placed in the sample in a 96well plate and cultured for $4 \mathrm{~h}$. Medium was then added, and the cells were incubated with a medium changed every 2-3 days. After the cells were cultured for 1, 3 and 7 days, the culture medium was discarded and cell viability was assessed using a Live/Dead cell viability kit. The Live/Dead assay was performed by adding $300 \mu \mathrm{l}$ of $4 \mu \mathrm{M}$ EthD-1 and $2 \mu \mathrm{M}$ Calcein AM in PBS per sample and incubating 30-45 $\mathrm{min}$ at room temperature. Fluorescence images were obtained by positive fluorescence microscopy. The Cell Counting Kit-8 assay (CCK-8) was used to quantify cell viability and proliferation after culturing the cells for 1, 3 and 7 days. To observe the morphology of cell attached on the material, the samples were rinsed with phosphate buffered saline to remove nonadherent cells and then fixed with $2.5 \mathrm{wt} \%$ glutaraldehyde for $1 \mathrm{~h}$. A series of gradient ethanol solutions $(50 \%, 70 \%, 90 \%, 95 \%$, and $100 \%)$ was used for sample dehydration, which was followed by the addition of pure isopentyl acetate. Cell morphology was then observed by SEM, and the samples were sputter-coated with a $10 \mathrm{~nm}$ thick gold film before measurements.

2.4.3 Cell differentiation. Osteogenic differentiation of attached cells was assessed by reverse transcription polymerase chain reaction (RT-PCR) at the gene and protein levels. After the cells were cultured for 7 and 14 days, they were harvested. Total RNA was extracted and reverse transcribed to cDNA. Expression levels of alkaline phosphatase (ALP), bone sialoprotein (BSP), collagen type I (Col I), Runx-2 and osteocalcin were quantified using RT-PCR.

\subsection{Implantation}

2.5.1 Animals. Thirty-six New Zealand white rabbits (aged 4-6 months and weighing $3.6 \pm 0.4 \mathrm{~kg}$ ) were obtained from the 
zoological animal center of our hospital, and 12 were in each group. The animals were housed under standard conditions, and all surgical procedures were performed in accordance with the ARRIVE guidelines, carried out in accordance with the National Institutes of Health guide for the care and use of laboratory animals (NIH Publications No. 8023, revised 1978) and approved by the IRB.

2.5.2 Surgery. The rabbits were anesthetized with an intramuscular injection of a $1: 1$ mixture of ketamine hydrochloride and xylazine hydrochloride, and both of the hind limbs were clipped and prepared for aseptic surgery. The procedures were performed under standard sterile conditions. A straight $2 \mathrm{~cm}$ skin incision was made over the portion of left femoral, and $2 \mathrm{~mm}$ diameter drills were used to create cylindrical defects in the diaphysis of each femur. Just before insertion of the implants, the hole was irrigated with saline to remove any bone shards. Implants were inserted in a line-to-line fashion. Irrigation with sterile saline was applied during the drilling of all bony defects. After implantation, the surrounding muscles were repositioned, and the subcutaneous tissues and the skin incision were repaired with resorbable sutures. The specimen was always implanted into the left limbs. The animals received a single intramuscular injection of clavulanate-potentiated amoxicillin at the time of surgery and were then inspected daily for clinical signs of complications or adverse reactions. The rabbits were allowed unrestricted cage activity postoperatively. No attempt was made to limit their activity after surgery.

2.5.3 Histological and histomorphometric analysis. The animals were sacrificed by intracardiac overdose of an anesthetic solution at 1, 4 and 12 weeks after implantations. Four rabbits in each group were sacrificed at every time point. All retrieved implant-containing bone fragments were dehydrated in a graded ethanol series (70\% to $100 \%)$ after fixation in $10 \%$ formalin solution for 2 weeks. They were then embedded without decalcification in a methylmethacrylate solution, which polymerized at $37{ }^{\circ} \mathrm{C}$ within 1 week. Then, the samples were subsequently cut and ground into $20 \mu \mathrm{m}$ transverse section using a modified interlocked diamond saw (Leica Microtome, Wetzlar, Germany) and stained with hematoxylin and eosin (H\&E); microscopic analyses were performed blind by one examiner using an optical microscope attached to a digital camera. The percentage of direct contact between the new bone and implant surface (bone-implant contact, BIC) was determined by ImageJ software (Microsoft, Maryland, USA). The mean values for all implants in each group were calculated and subjected to statistical comparisons. The implant sites were evaluated macroscopically in a semiquantitative manner with respect to hemorrhage, necrosis, exudation, neovascularization, and encapsulation.

\subsection{Statistical analysis}

The data were analyzed by Statistical Package for Social Sciences 17.0 software (SPSS 17.0, USA), the graphs were drawn by SPSS or GraphPad software (USA), and the results are presented as the mean \pm standard deviation (S.D). Statistical differences were evaluated by one-way ANOVA or Student's $t$-test. $P<0.05$ indicated a statistically significant difference.

\section{Results}

\subsection{Characterization}

Fig. 1a-c shows the optical microscopy image of the exterior face of the sample. The dense samples (Fig. 1a and d) had smooth surface topographies. The porous samples (Fig. 1b and c) had increased surface roughness, but the struts were well formed and continuous. The pore architectures of the samples were examined using SEM. Pore morphology, distribution and interconnectivity were demonstrated in images obtained by SEM (Fig. 1e and f). Pores of varying sizes were detected and three-dimensional connectivity between them was observed; some fractures were also presented (Fig. 1d-f). Detailed inspection of the SEM images confirms the mechanical integrity of cell strut with no absence of loose powder particles within the cell pores (Fig. 1d-f). The SEM images showed no interlayer differentiation when the exterior face of the samples was probed. After measurement and calculation, we found that the porosities of the two porous sample groups were (51.67 \pm $3.37) \%$ and $(75.37 \% \pm 2.51) \%$, which were expected, and the pore sizes of the two group were $290.87 \pm 134.38 \mu \mathrm{m}$ and 458.10 $\pm 172.29 \mu \mathrm{m}$, respectively.

\subsection{Mechanical properties}

Force displacement data were collected, from which the compressive stress/strain values were calculated and plotted. The elastic modulus was calculated from the slope of the compressive stress-strain curve in the linear elastic region (Fig. 2). The average compressive elastic modulus and strength of the samples were calculated and are given in Table 1. It is observed that both elastic modulus and ultimate compressive strength decrease with an increase in porosity, and there is a more significant drop in compressive strength. Therefore, samples with a porosity as high as approximately $75.37 \%$, and an elastic modulus of approximately $1.76 \mathrm{GPa}$ were successfully fabricated. These characteristics are similar to those of normal human trabecular bone, which provide adequate mechanical support without obvious stress shielding effect.

\subsection{In vitro biochemical assays}

3.3.1 Cell proliferation and attachment. Results of the Live/ Dead assay are shown in Fig. 3(a-c, e-g and $\mathrm{i}-\mathrm{k})$. Each image depicts a homogeneous distribution of living cells (green) on the sample surfaces with relatively few dead cells (red). Overall, all coatings showed good viability, and there was no evidence of dead cells at all times tested. The fluorescence images showed that cell proliferation increased with time, and significantly more cells in the porous groups were observed than the dense group (Fig. 3a-c, e-g and i-k). SEM showed that the cells proliferated and attached well on the surface of materials in all groups, whereas the cells proliferated faster and highly concentrated on the surface of materials in the porous groups. The cells presented spherical, triangular, elliptical, and 

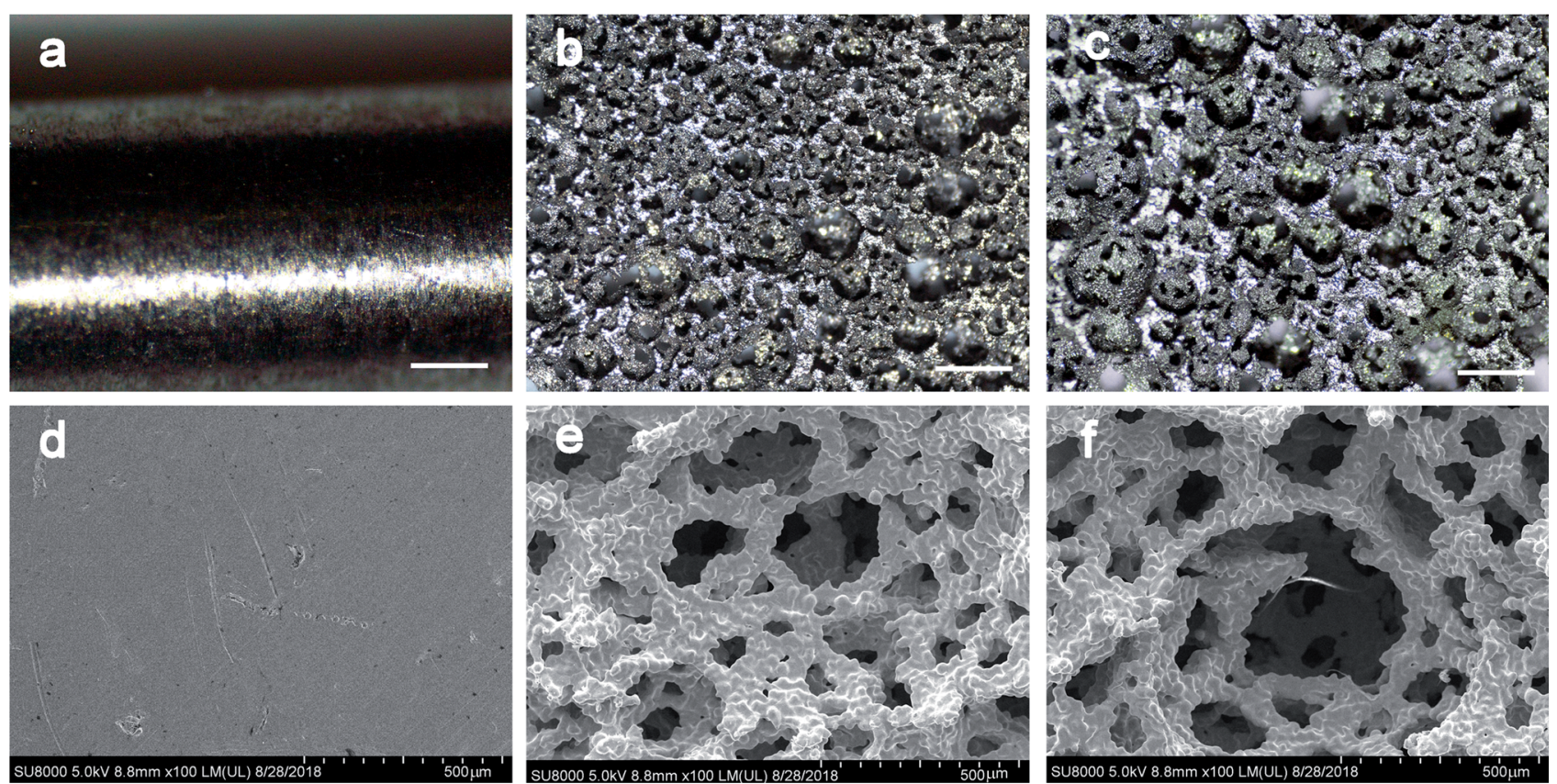

Fig. 1 Optical microscopy images of the exterior face of the samples: (a) dense group (b) $50 \%$ porosity group (c) $75 \%$ porosity group; and SEM images of the three groups: (d) dense group (e) $50 \%$ porosity group (f) $75 \%$ porosity group. Scale bar represents $500 \mu \mathrm{m}$.

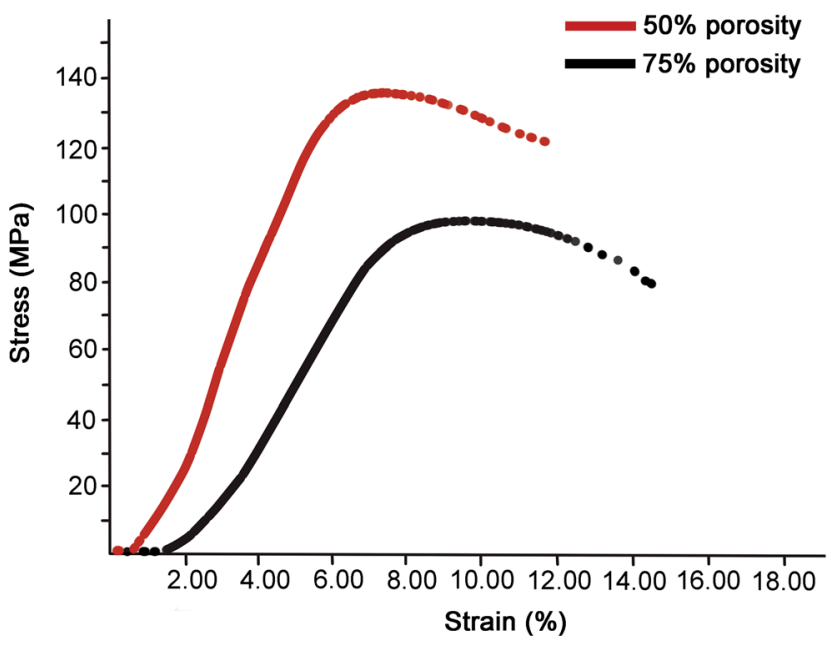

Fig. 2 Stress-strain curves of the two types of porous samples.

polygonal shapes. However, the cells on the surface of the $75 \%$ porosity group were growing from the edge into the pores and were interconnected confluently (Fig. $3 \mathrm{~d}, \mathrm{~h}$ and $\mathrm{l}$ ). In the quantitative CCK-8 assessment of cell proliferation, no significant differences between each group was observed from the first to the third day $(P>0.05)$, and each group showed increase of the OD values (Fig. 4 CCK-8). After 7 days of incubation, higher OD values were observed in the porous groups, especially the
$75 \%$ porosity group, compared to those of the dense group (Fig. 4 CCK-8). These results suggest that the porous samples have no cytotoxic effect on $\mathrm{OB}$ cells and the porous structure may even promote cell growth.

3.3.2 Osteogenic differentiation. Osteogenic differentiation capability was detected by RT-PCR after 7 and 14 days of incubation (Fig. 4). After 7 days of incubation, the expression of Runx-2, Col I and osteocalcin was significantly higher on the dense samples than the porous samples. The expression of ALP showed no statistically significant difference between groups. After 14 days of incubation, the expression of ALP, Runx-2 and osteocalcin was significantly up-regulated in cells seeded on porous samples, especially the $75 \%$ porosity group, and was statistically significant higher than that of the dense groups. However, the expression of BSP showed no statistically significant difference between the groups independent of topography (Fig. 4).

\subsection{Implantation}

All animals recovered uneventfully after surgery and reached their allocated time point with no infections or postoperative morbidity noted. No macroscopic signs of intolerance were observed for any of the implants, and no differences was observed in terms of hemorrhage, necrosis, exudation, or neovascularization between the test and control implants.

Table 1 Mechanical properties of three groups

\begin{tabular}{|c|c|c|c|c|}
\hline Elastic modulus (GPa) & $108.33 \pm 4.57$ & $3.31 \pm 0.30$ & $1.76 \pm 0.24$ & $F=1594.241, P<0.001$ \\
\hline Compressive strength (MPa) & $980.90 \pm 42.38$ & $134.92 \pm 13.79$ & $98.21 \pm 5.60$ & $F=1112.220, P<0.001$ \\
\hline
\end{tabular}



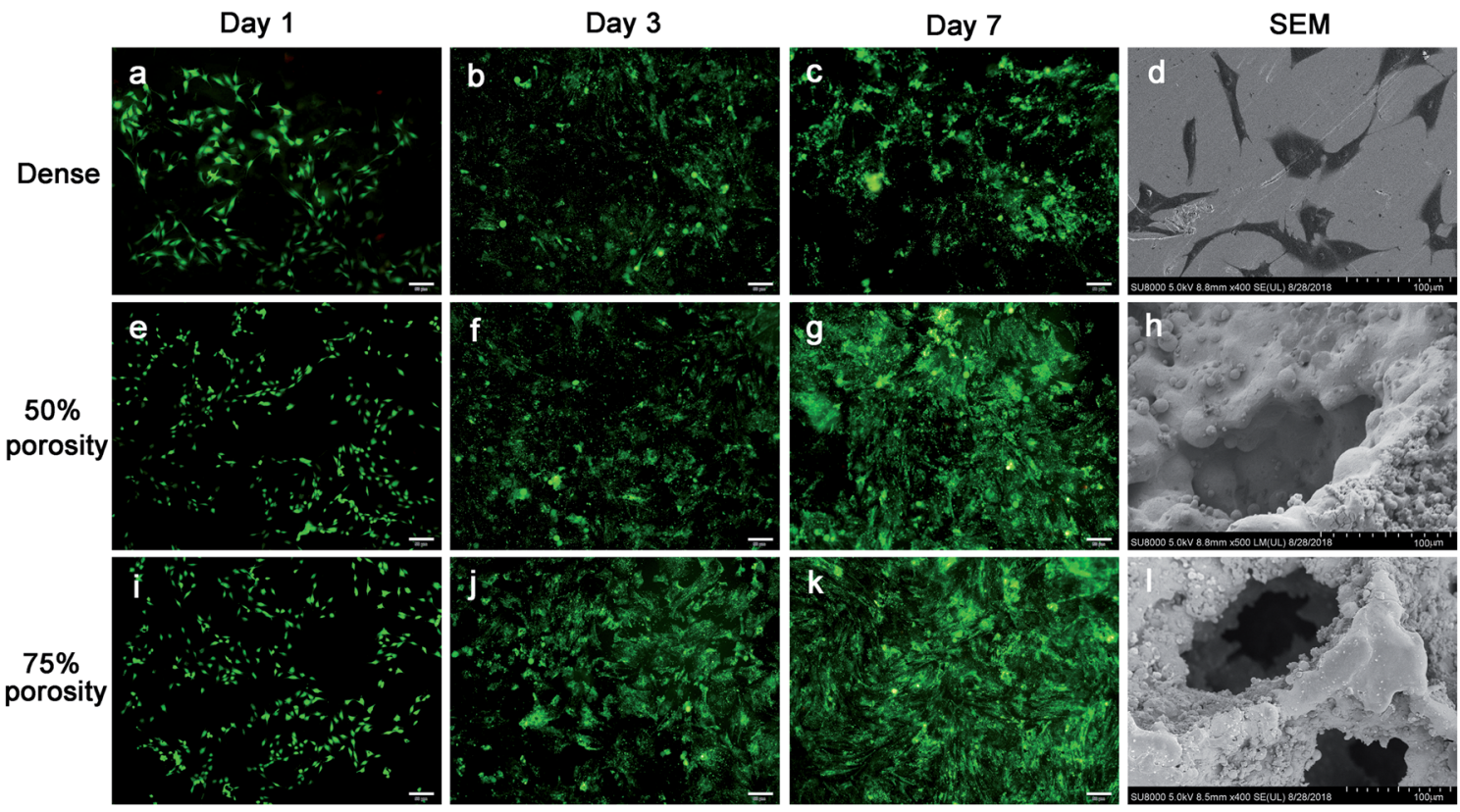

Fig. 3 Cell proliferation and Live/Dead fluorescence microscopy images after 1, 3 and 7 days of three groups: (a-c) dense group (e-g) 50\% porosity group (i-k) $75 \%$ porosity group; and the SEM images of cell attachment: (d) dense group (h) $50 \%$ porosity group (l) $75 \%$ porosity group. Scale bar represents $50 \mu \mathrm{m}$.

Bone formation was found to start from the host bone bed toward the implant in all implants. For the porous groups, 1 week after surgery, histological observations revealed that a small amount of new immature bone tissue grew from the rim of the bone defect and began to integrate with the periphery of the porous implants, with the direct deposition of newly formed bone onto the surface of the implants (Fig. $5 \mathrm{~d}$ and $\mathrm{g}$, bone tissue in red color and Ti alloy implant in black color). No material fragment or particles was detected in the surrounding tissue. After 4 weeks of implantation, histological evaluation indicated progressive growth of more newly formed bone from the femoral margins toward the center of the bone defect. The newly formed bone integrated well with the implant surface (Fig. 5e and h). A large part of the implant periphery was in


Fig. 4 The CCK- 8 results of cell proliferation and the expression of ALP, Runx-2, Col I, BSP and osteocalcin in three groups. 

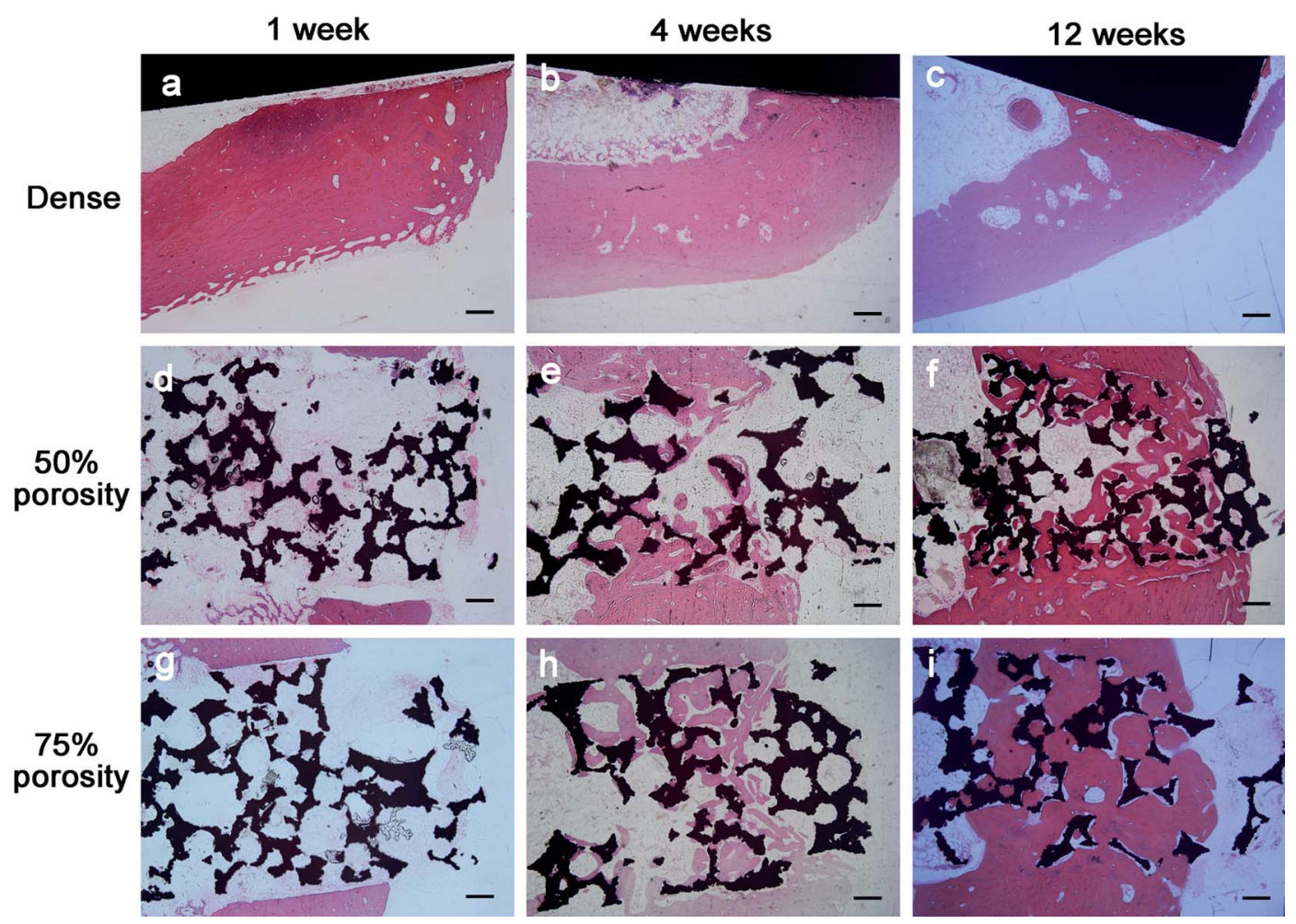

Fig. 5 Histological results after implantation of 1, 4 and 12 weeks in the three groups: (a-c) dense group (d-f) 50\% porosity group ( $g$-i) $75 \%$ porosity group. Scale bar represents $200 \mu \mathrm{m}$.

Table 2 The values of bone-implant contact in three groups at 4 and 12 weeks after implantation

\begin{tabular}{|c|c|c|c|c|}
\hline & Dense & $50 \%$ porosity & $75 \%$ porosity & Statistics \\
\hline $4 \mathrm{w}$ & $26.27 \pm 3.06$ & $37.47 \pm 2.51$ & $41.03 \pm 1.72$ & $F=28.665, P=0.001$ \\
\hline $12 \mathrm{w}$ & $37.20 \pm 3.70$ & $55.07 \pm 2.83$ & $64.90 \pm 3.05$ & $F=57.209, P<0.001$ \\
\hline
\end{tabular}

contact with the osteoid, or mineralized bone, and bone marrow. In general, smaller pores were completely filled with bone, whereas larger pores were partially filled. At 12 weeks, the newly formed bone has successfully bridged the bone defect, and the majority of the pores at the bottom part of the implants were filled with bone tissue, which was directly bridged with the bone defects (indicated in red color Fig. $5 \mathrm{f}$ and i). In addition, the process of bone remodeling was observed in all the implant sites. However, 1, 4 and 12 weeks after surgery, little new bone formation and moderate to extensive encapsulation were

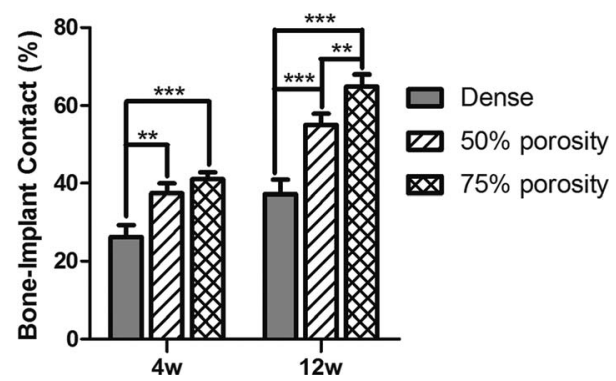

Fig. 6 The values of bone-implant contact in three groups at 4 and 12 weeks after implantation. observed for the control implants compared to the porous implants, which showed slight to moderate encapsulation, and no new bone was observed to grow into the control implants (Fig. 5a-c).

The quantitative data of bone formation are shown in Table 2. After 1 week of implantation, little bone was found at the bone-implant interface, and thus the data of 1 week were excluded from comparison. From Fig. 6, we indicated that, after 4 weeks of implantation, compared with the dense group, the $50 \%$ porosity and $75 \%$ porosity groups had higher boneimplant contact $(P=0.002$ and $P<0.001$, respectively), but there was no significant difference between the porous groups $(P=0.130)$. At 12 weeks, the extent of bone ingrowth and remodeling onto and inside the porous Ti alloy was greater than that at 4 weeks, and the $75 \%$ porosity groups had the highest bone-implant contact, compared with those of the dense and $50 \%$ porosity group (both $P<0.001$ ).

\section{Discussion}

Recently, porous metal has attracted interests because of its excellent biological properties. However, the porous alloy 
fabricated by the conventional sintering technique are often very brittle and are prone to crack propagation at low stresses, ${ }^{17,18}$ and the pore size, shape, volume fraction, and distribution are difficult to control. ${ }^{13}$ Conventional gelcasting is a well-established colloidal processing method, but the main disadvantages of the gelcasting approach are the large amount of liquid required to obtain a slurry of appropriate viscosity, the levels of shrinkage involved during drying of the bodies, the toxicity of the monomers (acrylate polymers) originally used and the necessity to atmosphere control. Other fabrication techniques that use foaming agents or molten metal suffer from typical limitations such as contamination, impurity phases, low porosity and high possibility of pore blocking..$^{17,19}$ Additionally, the manufacturing of porous titanium products is associated with difficulties, most notably the extreme chemical affinity of liquid titanium to atmospheric gases such as oxygen, hydrogen, and nitrogen, which eventually leads to strongly reduced ductility. ${ }^{7}$ In the present work, titanium foams were produced via gelcasting using a water-based powder suspension, where agar was used as gelling agent, Tergitol as foaming agent and Triton as liquid foam stabilizer. The powder suspensions were initially prepared using $\mathrm{Ti}_{6} \mathrm{Al}_{4} \mathrm{~V}$ powder associated with different concentrations and sizes of spacer particles, permitting the fabrication of implants with well-controlled porous structures, such as porosity and pore size. In addition, the technique prevents the absorption of atmospheric gases because the processing is carried out under an inert gas or vacuum atmosphere, and with two times of slow heating, resulting in high ductility of the porous Ti alloy.

\subsection{Microstructure and mechanical properties}

Microstructure and mechanical properties are critical properties in longevity of endosseous loading implants, ${ }^{20}$ which may be changed according to the composition of the material or pore containing topography. ${ }^{21}$ Pore diameter and porosity are important parameters in biological porous materials. ${ }^{2}$ However, there is no consensus on the optimal pore size and porosity. ${ }^{2,4}$ In general, porous materials with apertures from $150 \mu \mathrm{m}$ to $600 \mu \mathrm{m}$ can allow bone ingrowth. ${ }^{\mathbf{2 , 4 1 4}}$ High porosity with large pores can provide sufficient space for bone to grow into and facilitates an adequate supply of nutrients. ${ }^{22}$ The SEM results showed that the alloys in our study were porous, and three-dimensional connectivity between pores. The $75 \%$ porosity group in our study had an average diameter more than $400 \mu \mathrm{m}$, which is considered appropriate to promote cell proliferation. ${ }^{21,23}$ Porosity aims to mimic natural bone and can significantly decrease elastic modulus, ${ }^{21,24}$ therefore, it can help to reduce stress shielding between metallic implants and host bone tissue. The ideal porous implants should provide sufficient mechanical strength for stability and sufficient porosity for cell and tissue ingrowth. Generally, with increase in porosity, mechanical properties, such as stiffness and compressive strength, decrease. ${ }^{7}$ Thus, these requirements may lead to conflicting design goals, but a balance between the two can result in better implant performance. In this study, the $75 \%$ porosity samples had a high compressive strength of approximately 98.2 $\mathrm{MPa}$, which is close to that of cortical bone, ${ }^{3}$ the elastic modulus was approximately
1.76 GPa, which is close to that of cancellous bone. ${ }^{3}$ Hence, the porous alloys, especially the $75 \%$ porosity group, can alleviate the effect of stress-shielding to a large extent and provide a suitable environment for osteogenesis. ${ }^{25}$

\subsection{In vitro biochemical assays}

In this study, OB cells were selected for the comprehensive cytotoxicity evaluation of all samples to simulate the implantation of biomaterials into bone in vivo. ${ }^{26,27}$ To satisfy clinical requirements, biological materials must provide adequate internal space and surface area for cell growth to facilitate the adhesion and proliferation of cells, ${ }^{\mathbf{9}, 28}$ and the formation and deposition of the extracellular matrix (ECM). ${ }^{29}$ Porosity can affect the area of cell adhesion, ${ }^{30}$ whereas pore size and connectivity between pores influence the access and distribution of cells, nutrient supply, and production of metabolic products. ${ }^{31}$ Results of the CCk-8 assay and the fluorescence images of Live/Dead showed that cell proliferation on the surface of materials in the porous groups were significantly higher than that of the smooth-faced dense group at different time points, similar to previous studies. ${ }^{32,33}$ The cells grew best on the surface of samples in the $75 \%$ porosity group, in which some cells even grew deeply into the pores. The positive effect of porous biomaterials on cell proliferation is attributed not only to the three-dimensional structure, which mimics the design of the trabecular bone and supports tissue ingrowth, but also to the large surface area available for cell growth. ${ }^{34}$ In addition, the rough surface morphology within the pores also helps in biological tissue attachment and growth. ${ }^{34,35}$

Expression of ALP, Runx-2, Col I, BSP and osteocalcin was increased in porous groups after 14 days of incubation. Runx-2 is the major osteoblast transcription factors involved in osteoblast differentiation and bone formation, ${ }^{36}$ and Runx- 2 expression was lower in the porous groups after 7 days of incubation when comparing the dense samples, similar to previous data from Pereira. ${ }^{37}$ Additionally, osteocalcin is a marker of fully matured osteoblasts, ${ }^{38,39}$ in this study, osteocalcin is lower for cells on porous groups than those on dense group at 7 days, resulting in a delayed transition toward mature osteoblasts capable of mineralizing the ECM.40,41 The expression of BSP showed a significant increase over 14 days for all groups, suggesting that the bone cells initiated ECM production for all surfaces tested, similar to other studies. ${ }^{36,37}$ However, BSP expression showed no difference between groups independent of topography. The porous samples structure supports an enlarged and more suitable environment for bone-like tissue formation, ${ }^{26}$ and extends the lifespan of osteogenic cells and possibly their synthetic activity phase, ultimately leading to an increase in bone tissue formation.

\subsection{Implantation}

Implant surface properties have a direct role in osteogenesis at the bone-implant interface, influencing a series of coordinated events including protein adsorption, cell proliferation, and bone tissue deposition. ${ }^{42}$ The advantage of porous materials is their ability to provide biological anchorage for surrounding 
bone tissues and greater contact area at the implant-bone interface. ${ }^{1,43}$ In this study, the in vivo experiment revealed that bone started to grow from the host bone bed to the implants, and characteristics of direct adhesion (integration) of bone to implant were obvious. The general tissue response was similar for all three implant types, and in no cases was inflammatory infiltration consisting of mononuclear cells (lymphocytes) observed, nor was infiltration of neutrophils and eosinophils, which demonstrates the good biocompatibility of the implants used. No osteoclastic reaction was observed in the vicinity of the implant. A tight adhesion of implant to the bone was obvious without evidence of a foreign body reaction. There was a high degree of bone implant contact, that is, osseointegration, of the porous implants after long-term implantation in the experimental animals, and statistically significant differences in bone contact were found between the three types of implants, especially the $75 \%$ porosity group. The penetration depth of new bone regeneration increased rapidly with implantation time, and the defect was eventually bridged at week 12, demonstrating excellent osteoconductivity of the porous implants. The amount of formed bone in $75 \%$ porosity group was much higher than that in the dense and 50\% group, and many reported porous metals have been manufactured by other methods. ${ }^{\mathbf{4 4 , 4 5}}$ The in vivo results clearly showed significant increase in osteoconductive properties with increase in total porosity and increasing the pore size increased the amount of new bone growth. A high open pore volume allows more body fluids to be transported through the interconnected pores, which subsequently accelerates the healing process by allowing tissue to grow inside the implants and improves the biological fixation. ${ }^{22}$ Similar influence of porosity on bone ingrowth has also been reported in porous bioactive Ti implants. ${ }^{19,23}$

\section{Conclusion}

The porous titanium alloys fabricated by the new sintering method showed good biocompatibility. The basic requirement of clinical orthopedic implants was satisfied, which makes this type of porous alloy a good prospective material for biomedical application. The alloy with $75 \%$ porosity had the optimal mechanical properties, and suitable pore size and porosity, which allowed more bone ingrowth.

\section{Conflicts of interest}

There are no conflicts to declare.

\section{Acknowledgements}

This work was supported by The National Key Research and Development Program (grant numbers: 2016YFC1101905).

\section{References}

1 A. Artel, H. Mehdizadeh, Y. C. Chiu, E. M. Brey and A. Cinar, Tissue Eng., Part A, 2011, 17, 2133-2141.
2 Y. S. Amin, d. S. J. Van, Y. C. Chai, R. Wauthle, B. Z. Tahmasebi, P. Habibovic, M. Mulier, J. Schrooten, H. Weinans and A. A. Zadpoor, Biomaterials, 2014, 35, 6172-6181.

3 H. Kröger, P. Venesmaa, J. Jurvelin, H. Miettinen, O. Suomalainen and E. Alhava, Clin. Orthop. Relat. Res., 1998, 352, 66-74.

4 W. Mróz, B. Budner, R. Syroka, K. Niedzielski, G. Golański, A. Slósarczyk, D. Schwarze and T. E. Douglas, J. Biomed. Mater. Res., Part B, 2015, 103, 151-158.

5 G. Lewis, J. Mater. Sci.: Mater. Med., 2013, 24, 2293-2325.

6 P. Heinl, L. Müller, C. Körner, R. F. Singer and F. A. Müller, Acta Biomater., 2008, 4, 1536-1544.

7 J. Parthasarathy, B. Starly, S. Raman and A. Christensen, J. Mech. Behav. Biomed. Mater., 2010, 3, 249-259.

8 J. Wegrzyn, K. R. Kaufman, A. D. Hanssen and D. G. Lewallen, J. Arthroplasty, 2015, 30, 1008-1013.

9 Q. L. Loh and C. Choong, Tissue Eng., Part B, 2013, 19, 485502.

10 B. S. Van, Y. C. Chai, S. Truscello, M. Moesen, G. Kerckhofs, O. H. Van, J. P. Kruth and J. Schrooten, Acta Biomater., 2012, 8, 2824-2834.

11 V. D. S. Johan, d. J. Van, P. Olav, S. Amin Yavari, M. F. P. De Haas, J. H. Waarsing, H. Jahr, E. M. M. Van Lieshout, P. Patka, J. A. N. Verhaar and A. A. Zadpoor, J. Orthop. Res., 2013, 31, 792-799.

12 G. M. D. Peppo, A. Palmquist, P. Borchardt, M. Lennerås, J. Hyllner, A. Snis, J. Lausmaa, P. Thomsen and C. Karlsson, Sci. World J., 2012, 2012, 646417.

13 G. Ryan, A. Pandit and D. P. Apatsidis, Biomaterials, 2006, 27, 2651-2670.

14 H. Kienapfel, C. Sprey, A. Wilke and P. Griss, J. Arthroplasty, 1999, 14, 355.

15 S. Mullens, I. Thijs, J. Cooymans and J. Luyten, US Pat. US8992828, 2015.

16 J. B. Nebe, L. Müller, F. Lüthen, A. Ewald, C. Bergemann, E. Conforto and F. A. Müller, Acta Biomater., 2008, 4, 19851995.

17 I. H. Oh, N. Nomura, N. Masahashi and S. Hanada, Mater. Trans., 2002, 49, 1197-1202.

18 C. E. Wen, M. Mabuchi, Y. Yamada, K. Shimojima, Y. Chino and T. Asahina, Scr. Mater., 2001, 45, 1147-1153.

19 A. Bandyopadhyay, F. Espana, V. K. Balla, S. Bose, Y. Ohgami and N. M. Davies, Acta Biomater., 2010, 6, 1640-1648.

20 S. Sista, C. E. Wen, P. D. Hodgson and G. Pande, J. Biomed. Mater. Res., Part A, 2015, 97A, 27-36.

21 H.-C. Hsu, S.-K. Hsu, H.-K. Tsou, S.-C. Wu, T.-H. Lai and H. Wen-Fu, J. Mater. Sci.: Mater. Med., 2013, 24, 645-657.

22 D. Muller, H. Chim, A. Bader, M. Whiteman and J. T. Schantz, Stem Cells Int., 2010, 2011, 547247.

23 C. Caparrós, J. Guillemmartí, M. Molmeneu, M. Punset, J. A. Calero and F. J. Gil, J. Mech. Behav. Biomed. Mater., 2014, 39, 79-86.

24 L. Markus, B. Christian, T. Rainer and F. Horst, J. Biomed. Mater. Res., Part A, 2015, 102, 3677-3684. 
25 A. El-Hajje, E. C. Kolos, J. K. Wang, S. Maleksaeedi, Z. He, F. E. Wiria, C. Choong and A. J. Ruys, J. Mater. Sci.: Mater. Med., 2014, 25, 2471-2480.

26 E. M. Lotz, R. Olivares-Navarrete, S. Berner, B. D. Boyan and Z. Schwartz, J. Biomed. Mater. Res., Part A, 2016, 104, 31373148.

27 S. Minagar, J. Wang, C. C. Berndt, E. P. Ivanova and C. Wen, J. Biomed. Mater. Res., Part A, 2013, 101A, 2726-2739.

28 A. M. Vilardell, N. Cinca, N. Garciagiralt, S. Dosta, I. G. Cano, X. Nogués and J. M. Guilemany, Mater. Sci. Eng., C, 2018, 87, 41-49.

29 J. I. Rosales-Leal, M. A. Rodríguez-Valverde, G. Mazzaglia, P. J. Ramón-Torregrosa, L. Díaz-Rodríguez, O. GarcíaMartínez, M. Vallecillo-Capilla, C. Ruiz and M. A. Cabrerizo-Vílchez, Colloids Surf., A, 2010, 365, 222-229.

30 A. G. I. Rolando, T. Mclachlan, Y. Cai, S. Berner, R. Tannenbaum, Z. Schwartz, K. H. Sandhage and B. D. Boyan, Biomaterials, 2011, 32, 3395-3403.

31 M. F. Soláruiz, C. Pérezmartínez, J. J. Martíndelllano, C. Cardabatalla and C. Labaigrueda, Med. Oral Patol. Oral Cir. Bucal., 2015, 20, 88-93.

32 P. Valerio, M. H. R. Guimaráes, M. M. Pereira, M. F. Leite and A. M. Goes, J. Mater. Sci.: Mater. Med., 2005, 16, 851.

33 P. R. Anil Kumar, H. K. Varma and T. V. Kumary, Acta Biomater., 2005, 1, 545-552.
34 J. P. St-Pierre, M. Gauthier, L. P. Lefebvre and M. Tabrizian, Biomaterials, 2005, 26, 7319-7328.

35 S. Sista, C. Wen, P. D. Hodgson and G. Pande, Mater. Sci. Eng., C, 2013, 33, 1573-1582.

36 J. Isaac, A. Galtayries, T. Kizuki, T. Kokubo, A. Berda and J. M. Sautier, Eur. Cells Mater., 2010, 20, 178-196.

37 K. K. Pereira, O. C. Alves, N. A. Jr, F. S. de Oliveira, J. H. Yi, O. Zaniquelli, C. Wolfbrandstetter, D. Scharnweber, F. Variola and A. Nanci, J. Periodontol., 2013, 84, 1199-1210. 38 C. Masaki, G. B. Schneider, R. Zaharias, D. Seabold and C. Stanford, Clin. Oral Implants Res., 2010, 16, 650-656.

39 Y. Hu, X. X. Tang and H. Y. He, J. Clin. Rehabil. Tissue Eng. Res., 2013, 12, 6527-6534.

40 E. P. Ferraz, J. C. Sa, P. T. de Oliveira, A. C. Jr, M. M. Beloti and A. L. Rosa, J. Biomed. Mater. Res., Part A, 2014, 102, 991-998.

41 A. P. Maartens and N. H. Brown, Curr. Top. Dev. Biol., 2015, 112, 233-272.

42 B. Yin, B. Xue, Z. Wu, J. Ma and K. Wang, Am. J. Transl. Res., 2018, 10, 474.

43 U. Saran, S. G. Piperni and S. Chatterjee, Arch. Biochem. Biophys., 2014, 561, 109-117.

44 L. M. Vasconcellos, D. O. Leite, F. N. Oliveira, Y. R. Carvalho and C. A. Cairo, Braz. Oral Res., 2010, 24, 399-405.

45 P. Thomsen, J. Malmström, L. Emanuelsson, M. René and A. Snis, J. Biomed. Mater. Res., Part B, 2009, 90B, 35-44. 